\title{
BMJ Open Factors promoting physical activity in women with fibromyalgia: a qualitative interview study
}

\author{
Anette Larsson (D), Caroline Feldthusen, Kaisa Mannerkorpi
}

To cite: Larsson A, Feldthusen C, Mannerkorpi K. Factors promoting physical activity in women with fibromyalgia: a qualitative interview study. BMJ Open 2020;10:e031693. doi:10.1136/ bmjopen-2019-031693

- Prepublication history for this paper is available online. To view these files, please visit the journal online (http://dx.doi org/10.1136/bmjopen-2019031693).

Received 15 May 2019 Revised 26 March 2020 Accepted 26 June 2020
Check for updates

(C) Author(s) (or their employer(s)) 2020. Re-use permitted under CC BY-NC. No commercial re-use. See rights and permissions. Published by BMJ.

Institute of Neuroscience and Physiology, Section of Health and Rehabilitation, Physiotherapy, Sahlgrenska Academy, University of Gothenburg, Gothenburg, Sweden

Correspondence to Anette Larsson; anette.e.larsson@vgregion.se

\begin{abstract}
Objectives To gain deeper knowledge of factors promoting physical activity in women with fibromyalgia. Design A qualitative study based on semistructured in-depth individual interviews. Analysed using qualitative content analysis.

Participants Fourteen women with fibromyalgia, age 38-65, recruited from a previous randomised controlled trial investigating the effects of person-centred progressive resistance exercise compared with relaxation therapy. Setting Interviews were conducted in a hospital setting. Results The analysis resulted in four categories: $a$ desire to be physically active, finding the proper level and creating proper conditions, managing pain and getting it done.

Conclusion This study reveals several factors both personal and environmental, which promote the ability to be physically active when living with pain and other symptoms of fibromyalgia. The participants expressed that, although they had a desire to be physically active, they needed support and guidance from a professional with adequate knowledge to help them find the proper level of exercise. They also expressed a need for the professional to understand their preferences, and to use these preferences as a basis for creating the proper conditions, helping them learn to manage pain and supporting them in getting the exercise done.
\end{abstract}

\section{INTRODUCTION}

Fibromyalgia (FM) is a musculoskeletal disorder with a prevalence of $2 \%$ in the general population. It is several times more common among women than men, and its prevalence increases with age. ${ }^{12} \mathrm{FM}$ is a heterogeneous and complex condition, ${ }^{2}$ and although pain is the most prominent symptom, FM is also associated with impaired physical capacity, ${ }^{3-5}$ activity limitations, ${ }^{6}$ fatigue and distress. ${ }^{27}$

Physical activity is defined as 'any bodily movement produced by skeletal muscles that require energy expenditure', ${ }^{8}$ and current recommendations for adults to receive health benefits from physical activity consists of 150 min of moderate-intensity aerobic activity together with muscle strengthening activities twice a week. ${ }^{9}$ Despite the well-known effects, these recommendations appear to be
Strengths and limitations of this study

All participants had previous experience of physical activity which made it possible for them to give a nuanced picture of their experiences.

- Qualitative content analysis is a well-established method used in this study to analyse promoting factors for physical activity in women with fibromyalgia.

- All participants were women with fibromyalgia in working age which may limit the generalisability of the results.

difficult to fulfil for healthy persons, ${ }^{10}$ and even more so for persons challenged by pain and fatigue. ${ }^{11}$

According to European League against Rheumatism 2016 revised evidence-based treatment recommendations for FM, there is a 'strong for' recommendation to incorporate individually adjusted exercise as treatment in FM because of the well-documented positive effects on symptoms, physical capacity and health-related quality of life. ${ }^{12}$ Studies have shown that even light intensity physical activity can improve symptoms and physical capacity in persons with FM. ${ }^{1314}$ Our previous studies of pool exercise ${ }^{1516}$ Nordic walking ${ }^{17}$ and resistance exercise ${ }^{18}$ for women with FM show positive effects on disease specific symptoms, level of physical activity, physical capacity and health-related quality of life.

Few long-term follow-up studies on exercise have been published. ${ }^{19}$ It appears to be easier for many patients to maintain low-intensity exercise $^{20}$ than exercise of higher intensity. ${ }^{18}$ Long-term follow-up after pool exercise showed that most participants had continued to exercise through regular outdoor walks with walking speed adjusted to their limitations. ${ }^{20}$ The long-term follow-up after the Nordic walking intervention showed that most participants had lowered their exercise intensity, but that they still walked outdoors. ${ }^{21}$ Long-term follow-up of the resistance exercise showed that few of the participants had 
continued to exercise in a gym. ${ }^{18}$ It seems that managing to exercise independently on a more strenuous level is difficult for most patients.

In this study, we were interested in seeking deeper knowledge about the factors that promote physical activity at any intensity in women with FM with interest in being physically active. Physiotherapists are ideally placed to promote safe and healthy physical activity ${ }^{22}$ and this knowledge is needed in the process of developing strategies to support women with FM in their struggle to be physically active and to maintain physical activity habits.

The aim of this study was to search for deeper knowledge of factors promoting physical activity in women with FM.

\section{METHODS}

\section{Study design}

Qualitative semistructured in-depth individual interviews ${ }^{23}$ were performed and analysed using qualitative content analysis. ${ }^{24}$

\section{Participants}

The participants were recruited from a cohort of 40 women with FM who had previously participated in a study investigating the effects of supervised resistance exercise and relaxation therapy in West Sweden, during 2010-2011. ${ }^{18}$ The inclusion criteria were being a woman with FM according to the American College of Rheumatology 1990 criteria, ${ }^{7}$ and having participated at least 10 times in either of the interventions. A total of 28 women $(70 \%)$ fulfilled the inclusion criteria and were contacted by mail with information about the study. The letter was followed up with a telephone call to confirm participation and schedule the interviews. Of the 18 women who were reached by telephone, 12 agreed to participate and were interviewed. The remaining six women declined to participate because of time limitations. In order to reach at least two more participants, another letter was sent to the women whom we did not reach by telephone $(n=10)$. Two of these women expressed interest and were interviewed, and so in total 14 interviews were performed (figure 1).

\section{Demographic characteristics}

Demographic characteristics included age, symptom duration, work status, Fibromyalgia Impact Questionnaire $(F I Q)$, a disease specific self-reported questionnaire that comprises 10 subscales of disabilities and symptoms ranging from 0 to 100 . The total score is the mean of 10 subscales. A higher score indicates a lower health status. ${ }^{25}$ The FIQ-total score can be divided into three groups of impairment: mild (<39 points), moderate ( $\geq 39$ to $<59$ points) and severe ( $\geq 59$ points), ${ }^{26}$ current Global pain rated on a plastic $0-100$ visual analogue scale with a movable cursor along a line and anchors at the extremes. The participant was asked to rate her global pain intensity ranging from 'no pain at all' to 'worst imaginable pain', and also level of leisure time physical activity on a leisure time physical activity index (LTPAI). ${ }^{27}$

\section{Data collection}

The interviews were performed by an experienced physiotherapist $(\mathrm{CF})$ working both as a healthcare professional and as a researcher. Interview data were gathered through semistructured individual interviews that took place in the physiotherapy premises at Sahlgrenska University Hospital, April-November 2016. The interviewer followed an interview guide with open-ended questions (box 1). All interviews began with a joint open introduction and the question: 'We are interested in gaining more knowledge of the factors that persons with FM experience as promoting or hindering their exercise or being physically active. Can you tell me how you exercise today?' The interviewer followed the respondent's reasoning and the study questions and invited the participant to add, confirm and clarify any aspects discussed. The content of interview material was extensive which indicates that the number of interviews was enough for saturation. Each interview lasted for approximately 1 hour and was audio recorded and then transcribed verbatim by an experienced medical secretary.

\section{Data analysis}

The transcribed interviews were analysed by qualitative content analysis which includes both interpretation of the

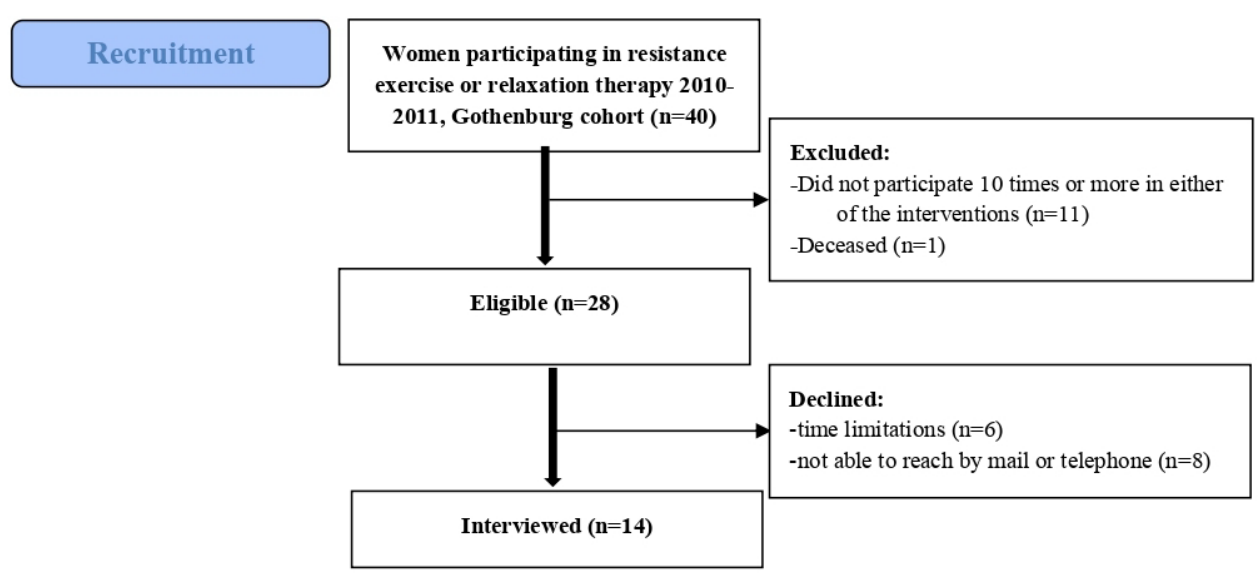

Figure 1 Flow diagram of the recruitment process. 


\section{Box 1 Interview guide}

We are interested in gaining more knowledge of the factors that persons with fibromyalgia experience as promoting or hindering their exercise or being physically active. Can you tell me how you exercise today?

What works well with this type of exercise?

- Which problems/difficulties have you encountered in relation to exercising?

- How did you handle these problems/difficulties?

Which factors motivates you to continue with your exercise?

Have you tried any other type of exercise?

- Can you tell me what problems you encountered?

- Do you think that modification of the exercise would have made it possible for you to continue?

Have you ever tried to exercise on a more strenuous level?

- What kind of support would you need to be able to manage strenuous exercise?

Anything else you would like to add?

manifest content close to the text and deeper interpretations of its latent underlying meaning. ${ }^{28} 29$ The analysis was performed by hand. First, the interviews were read through several times in order to obtain a sense of the whole. The unit of analysis consisted of whole interviews, and no parts were excluded from the analyses. Second, guided by the research question of factors promoting health-enhancing physical activity, meaning units were derived from the text, condensed and abstracted. ${ }^{28}$ The abstracted meaning units were then developed into subcategories and categories. The analytical process moved continuously back and forth between the whole and parts of the text. ${ }^{28}$ Tentative subcategories and categories were discussed and elaborated between all authors until consensus was reached. Cooperation between the researchers was assumed to increase the credibility of the analysis. The results from the analysis are presented as subcategories and categories, illustrated by citations from the interviews.

\section{Patient and public involvement}

Patients participating in resistance exercise and relaxation therapy ${ }^{18}$ were invited to a reunion where both promoting and hindering factors were discussed, after which a decision was made to make the present study and to invite participants from both groups to be interviewed.

\section{RESULTS}

Characteristics of the study participants are given in table 1. When the FIQ total score was divided into three groups of impairment, one participant had mild impairment, seven participants had moderate impairment and six participants had severe impairment.

The results show that regular physical activity was promoted by a desire to be physically active, finding the proper level and creating proper conditions, managing pain and getting it done. In the following sections, each category will be presented with subcategories, table 2 .
Table 1 Demographic data of the participants included in the study $(n=14)$

\begin{tabular}{lll}
\hline Variables & Median (min; max) & N (\%) \\
\hline Age (years) & $60.5(38 ; 65)$ & \\
Symptom duration (years) & $15.0(7 ; 32)$ & $12(86)$ \\
Living with an adult (yes) & & $12(86)$ \\
Born in Sweden (yes) & & \\
Education & & $2(14)$ \\
$\quad \leq 9$ years & & $7(50)$ \\
$\quad 10-12$ years & $5(36)$ \\
$\quad>12$ years & & $9(64)$ \\
$\quad$ Working (yes) & & \\
Global pain (0-100) & & \\
FIQ total (0-100) & $58(11 ; 79)$ & \\
LTPAl total (hours) & $57.9(35 ; 73)$ & $3.5(1 ; 10)$ \\
\hline
\end{tabular}

FIQ, Fibromyalgia Impact Questionnaire; LTPAI, LeisureTime Physical Activity Index.

The numbers appearing before the quotations refer to individual participants.

\section{A desire to be physically active}

The participants described being driven by a desire to be physically active. They expressed a need to be physically active, knowing that it was good for them, and described positive effects experienced during and after physical activity. Their desire to be physically active was strengthened by their fear of getting worse. Positive experiences of physical activity and the self-image of being a physically active person prior to being ill appeared to further strengthen this desire.

Table 2 Factors promoting physical activity in women with fibromyalgia

\begin{tabular}{ll}
\hline Category & Subcategory \\
\hline $\begin{array}{l}\text { A desire to be physically } \\
\text { active }\end{array}$ & $\begin{array}{l}\text { A need to be physically active } \\
\text { Fear of getting worse } \\
\text { Previous good experiences of } \\
\text { physical activity }\end{array}$ \\
$\begin{array}{ll}\text { Finding the proper level and } \\
\text { creating proper conditions }\end{array}$ & $\begin{array}{l}\text { Need of adjustment } \\
\text { Need of adequate knowledge } \\
\text { and understanding }\end{array}$ \\
Managing pain & $\begin{array}{l}\text { Accepting pain } \\
\text { Balancing pain }\end{array}$ \\
& Prioritising \\
Getting it done & $\begin{array}{l}\text { Not giving up } \\
\text { Exercise that feels good } \\
\text { Support to get it done } \\
\text { Accessibility } \\
\text { Continuity }\end{array}$ \\
\hline
\end{tabular}




\section{A need to be physically active}

Most participants said they felt a need to be physically active because their earlier experiences had given them the knowledge and expectations that it was good for them. Being physically active made them feel happy, as if they had been kind to their bodies. Some participants also described how physical activity had become a habit, saying that they felt an urge to be physically active on a regular basis, in order to avoid feeling bad, both physically and mentally.

(5)... I know that physical activity makes me feel better, I don't feel good when Im sitting at home on the couch. That won't make me better, it'll make me worse, and I need to be physically active a few times a week...

Most of the participants described positive experiences during or after physical activity such as improved wellbeing and quality of life. Although they felt tired after physical activity, they also felt capable and content with themselves. They experienced physical effects including improved endurance, balance, strength and health, as well as psychological effects such as being able to handle stress better, being happier and forgetting about their illness. They described improvement in symptoms-less pain, better sleep and reduced stiffness, and said that being physically active helped them to manage activities of daily life better.

(10)...When I've been physically active and my body is tired...That is a wonderful feeling....and I'm so content with myself, I've been a good girl. It's a feeling of happiness and my body feels good

\section{Fear of getting worse}

Besides describing their need to be physically active and the positive experiences related to physical activity, the participants also expressed the feeling that their body had let them down, and said that things that were previously easy to do now required large effort. They described being driven by the fear of getting even worse, and becoming unable to manage activities of daily life, confined to a chair or bedridden. They felt resentment, sadness and frustration about losing their strength and energy, and expressed fear of the pain getting worse if they stopped being physically active.

(1) ....because I have a strong need to be physically active, that's something I feel in my body. When I get sick I still have to go out and walk a little. There's some kind of fear in me to be lying there or to be seated...

\section{Previous good experiences of physical activity}

Many participants said that they had been physically active since childhood and considered themselves to be physically active persons. They described how they had both physical and mental memories of being able to be physically active, and expressed how they longed to regain the ability and the energy that they had before they became ill.

(2) ...I want to go there and try all the time because I long for it. I'm still climbing the walls even though it's been 8-9 years since I became ill, it doesn't matter. There's a mental and physical memory...

\section{Finding the proper level and creating proper conditions}

The participants described a need to adjust their exercise in order to avoid activity-induced pain. They accentuated the need for professional support in finding the right level of exercise, and referred to the specific exercises chosen, to the loads and to the pace.

\section{Need of adjustment}

The participants described the consequences of overload when being physically active and expressed the importance of adjusting the exercises, the load and the pace. Overload would cause increased pain, sometimes for several days. They described that if they could start low, progress slowly and increase their loads at a reasonable rate, they would be able to exercise without increased pain or fatigue. They also described how they had tried and failed and that this was difficult to manage on their own or in community-based exercise facilities.

(12) ... I can't just go to any gym, or any class, it doesn't work or I don't. I just don't, because I know that it doesn't work. I have tried, been there -'Of course you should try bodypump', and this and that, but I mean yeah right -no, I can't...

\section{Need of adequate knowledge and understanding}

The participants described that they needed to find information themselves and learn how to adjust their physical activity level in order to avoid increased pain due to overload. They expressed that there is commonly a lack of knowledge about FM among healthcare professionals and personal trainers and some of the knowledge is incorrect. When being met with adequate knowledge, they felt encouraged and secure in how to exercise. They expressed a wish to be able to exercise within healthcare, or wanted some kind of adjusted community-based group-exercise.

(2)...I might be able to be there if I got help from someone when I need it, to support me and help me progress slowly and somehow change the exercises a bit, but not too much, and someone to consult with. Some kind of physiotherapist or personal trainer who's available to consult and who has knowledge about the disease...

Besides knowledge, the participants expressed a need for support, characterised by understanding and responsiveness during exercise. They said they needed to have someone to seek advice from during setbacks, who could support them in maintaining their exercise, 
while allowing them to reduce the loads when necessary without making them feel guilty. They described how a lack of support and understanding would make them lose their confidence.

(4)...It (the exercise) was hard but still I thought the physiotherapist made sure that we reduced the load if we came into a period where... and that we would do... you didn't feel forced...to do something you couldn't do...it was so nice to feel that they were so understanding... I appreciated that...It can be quite difficult if you have someone who...yes, you can do this... because you can't and then you just go home and feel sad...

\section{Managing pain}

The participants described how they had to relate to and manage their pain, and how they used mental and physical strategies to manage pain during and following physical activity.

\section{Accepting pain}

The participants expressed the importance of learning to live with pain as a part of life and accepting the fact that some days they could be physically active while other days they were unable to do anything. They accentuated the importance of setting their own limits, not being afraid of the pain and not letting pain control their life. They knew they might have more pain following physical activity, but felt that they could accept increased pain when engaging in meaningful or enjoyable activities. Having a positive attitude and not feeling sorry for oneself was expressed as important to handle the increased pain.

(13)....I've accepted my pain. It's there like... and I have to try to divert it...I do things I enjoy, but I'll have to pay for it, and that goes for both physical activity and other physical...but it's worth it, I can take it...

\section{Balancing pain}

The participants described how they avoided strenuous physical activities since it was difficult for them to limit themselves and avoid overwork. Often they felt good while being physically active but, a day or 2 days after, they would suffer from increased pain and severe fatigue. The pain was described as varying from day to day, which demanded adjustment and self-discipline to manage these fluctuations. Some participants avoided scheduled physical activities since they were unable to predict how they would feel the following day or next week. They expressed that it was important to lower their demands and acknowledge that what they could do was good enough. The participants described different strategies to balance pain following physical activity such as analgesics, heat, movements to relieve stiffness, taking time to rest, breathing techniques, pacing of activities and mindfulness.
(9)...I guess it (activity-induced symptoms) is like a hangover, I don't really know how that is, but...You sort of drink and drink, and everything feel so good and the day after you're completely knocked out. Yes, you can compare it to that...

\section{Prioritising}

The participants described having to set priorities in order to cope with their energy levels, and avoid overload and increased pain. They did not have enough energy and time to manage all of family, work and exercise, and participants who were working said that work was always their highest priority. They found it beneficial to be able to exercise during working hours, since they were often too tired after work to have the energy to be physically active. Sometimes, they avoided physical activity because they were afraid of increased pain and not being able to go to work the following day.

(7)...It's really difficult...when you work and have a family. If you hadn't had a family, you could have added another $25 \%$ to exercising, but if you have a family, they want at least something of you (laughs)...

\section{Getting it done}

The participants expressed the importance of not giving up. Despite their desire to be physically active, they had to struggle to stay motivated. It was important for them to find their own way and do something enjoyable. The chosen activities varied substantially and the participants described engaging in activities like dancing, cycling, walking outdoors, gardening, swimming and so on. They described the importance of external support from family and friends to motivate them and accentuated the importance of exercise being accessible and continuous.

\section{Not giving up}

The participants highlighted the importance of seeing opportunities instead of difficulties, and trying to do something even if they could not do everything. They emphasised the importance of not giving up although they felt that they had to struggle their way back after a setback.

(5)...it's important not to give up. Not feeling, 'No I can't' because there's something you can do...

\section{Exercise that feels good}

The participants expressed that doing something enjoyable was a major facilitator for physical activity. Factors that could enhance the experience and increase motivation included music, and an inspiring group leader. Being physically active outdoors made them feel free and relaxed, and exercise in warm water was appreciated by several participants. It was important to find a place to exercise where they felt safe and at home. Some of the 
participants avoided the gym because they felt that other people looked at them judgingly when they had to rest or used light or no loads.

\section{Support to get it done}

Several participants described how social support could motivate them to get the exercise done, like exercising together with their partners, with a friend or in a group. Others described that they were able to save their energy for physical activity because their husband took care of the household chores. Some participants expressed that it was important to have a scheduled meeting with someone expecting them, because that would make it more difficult to cancel or not to attend. Having a dog or some kind of gadget also motivated them to be physically active.

(5)...they're always positive when you arrive...its nice then, you feel that you're noticed...I have a great need to be noticed...

\section{Accessibility}

The participants expressed the importance of exercise being accessible and affordable. They said that if they could exercise near their home, it would be easier to get it done, and also save energy and reduce travel expenses. Economic factors also influenced their possibility to exercise and the participants requested exercise alternatives at reasonable cost based on their prerequisites. Several of them said that unlimited access to exercise within healthcare would enhance their ability to exercise.

(3)...I'd like it to be nearby... Then you know you'll get it done... It's much easier when it's closer...

\section{Continuity}

The participants expressed a need for continuity, because they felt as if they had to start all over again after a break. They wanted to be able to exercise without being interrupted and accentuated the importance of having a routine, plan for physical activity, in order to get it done.

(2)...It doesn't work for someone who's chronically ill when there's so many of us... and the summer time, yes, then they close and empty the pool...or at Christmas, everything's closed again. I need it all the time...that's something I feel is very important...continuity, never being interrupted... it just goes on...

\section{DISCUSSION}

Management of exercise is troublesome for patients with FM due to pain, ${ }^{2}$ impaired physical capacity, ${ }^{5}$ fatigue ${ }^{2}$ and activity-induced pain. ${ }^{30}$ The participants in the present study described setbacks as a consequence of overload and how they continuously had to prioritise among activities and sometimes avoid strenuous activities in order to avoid activity-induced pain. Despite the evident difficulties, the participants perceived positive effects of physical activity and struggled with their ambition to engage in physical activity.

The aim of this study was to investigate which factors promote physical activity in women with FM. Four categories emerged from the interviews: a desire to be physically active, finding the proper level and creating the proper conditions, managing pain and getting it done.

\section{A desire to be physically active}

The participants described their previous positive experiences from being physically active and accentuated their self-image of being physically active persons. This is in line with previous studies where participants with chronic musculoskeletal pain described themselves as physically active persons and expressed previous and present physical and mental benefits of being physically active. ${ }^{31} 32$ Studies show that this kind of insight only can emerge from personal experiences of enjoyment of the physical activity itself and the perceived benefits of being physically active, ${ }^{33} 34$ therefore it appears to be important to support persons to find the resources to be physically active so that they can experience these positive effects.

The present study shows how earlier and present positive experiences of accomplishing exercise-related tasks together with support from a person with adequate knowledge contributed to the person continuing to exercise, despite disease-related obstacles. Earlier positive experiences following exercise and earlier and present positive experiences of managing to exercise are two of the core elements of exercise self-efficacy. ${ }^{35}$ A third component to enhance exercise self-efficacy is support and advice from someone trustworthy. Higher exercise-self efficacy have been found to associate with engagement in physical exercise and to predict continued exercise engagement in people with $\mathrm{FM}^{36}$

\section{Finding the proper level and creating the right conditions}

Our participants expressed that it was essential to have support to be able to exercise at the appropriate level in order to avoid activity-induced pain following physical activity. Being met with adequate knowledge and understanding was another important factor. This finding is supported by earlier studies showing that patients with chronic pain express the need for individually tailored support and guidance, preferably from healthcare, in figuring out suitable activities and increasing their motivation. $^{32} 37$

According to person-centred ethics, communication between patient and healthcare provider involves interaction and dialogue to create a common understanding of the experience of the illness and its consequences. ${ }^{38}$ The participants in the present study described that when they tried to exercise in the same manner as prior to getting ill, they repeatedly strained themselves until they gave up, and sometimes decided to avoid all strenuous activities. When the participants felt listened to and met with adequate knowledge, this made them feel secure and encouraged. Understanding, support and having 
someone to seek advice from were, in this study, considered important to be able to perform physical activity and these results are similar to those found in a qualitative study comprising physically active persons with rheumatoid arthritis. ${ }^{39}$

\section{Managing pain}

To be able to exercise, the participants described the importance of managing increased pain following exercise. The participants in the present study had developed different strategies to manage their pain and felt that they could manage increased pain following a meaningful or enjoyable activity. These results differ to some extent from a recently published study among patients with chronic pain, where the participants described hesitating over, and avoiding physical activity due to the discomfort that followed. ${ }^{40}$ However, the participants in the present study described how they had to make decisions and prioritise, and how this could result in a conflict between attainment of life goals and pain control. This has also been found in another study where the participants described how they constantly had to take care to avoid overuse of their limited resources, and adjust their activities to the unpredictability of their symptoms. ${ }^{41}$ The women in this study who were working were very definite about how work was their highest priority. In order to manage their work, they sometimes had to make a calculated choice to avoid physical activity in order to avoid the risk of activityinduced pain or fatigue. The same result has been found in another study of working women with FM where the participants described work as meaningful and their joy of life and their motivation to keep on working was high. ${ }^{41}$

The participants in the present study had lived with their pain for several years, which may have contributed to their insight regarding the benefits of accepting pain as a part of life and realising that some days they could be active and some days they could do nothing. Acceptance of pain has been shown to be associated with better physical, social and emotional functioning ${ }^{42}$ and requires the ability to focus on what is possible when living a life with chronic pain as well as re-evaluating priorities. ${ }^{43}$

\section{Getting it done}

Our participants underlined the importance of doing something enjoyable. This was also described in another study where the participants willingly engaged in activities that they knew could cause increased pain rather than missing out on the opportunity to do something they enjoyed. $^{43}$

Women with FM are a vulnerable group as living with chronic pain leads to significant consequences on a personal and social level as well as on a societal level. Since there is no curative option available, treatment focuses on reducing pain and disability and maximising quality of life despite symptoms. Our results suggest that this requires accessibility and continuity, preferably within healthcare. Similar results has been found in a study investigating physical activity in patients with chronic pain where the patients expressed that they desired extensive, active and continuous support from healthcare providers. ${ }^{40}$

\section{Methodological concerns}

Women with FM form a heterogeneous group, comprising several subgroups, ${ }^{44}$ of which some try to avoid physical activities due to activity-induced pain, while others are active to a greater or lesser extent. The focus of the present study was women with FM who engage in physical activity at any intensity from time to time. Participants were therefore recruited from a treatment study including resistance exercise or relaxation. Participants from both groups were invited to the study. The physical activity level of the participants ranged from 1 to 10 hours a week, and they reported moderate to severe activity limitations which indicates that this group were representative for the general FM population. The interviews were performed in the physiotherapy premises by a physiotherapist trained in person-centred care. It might be appropriate to assume that the interviewing involved the researcher's preunderstanding. To ensure consistency in data collection, all the interviews were initiated with the same question and followed a semistructured interview guide. We believe that the categories in this study contributes to a deeper understanding of factors promoting physical activity in women with FM. It might be difficult to generalise the results to other populations of FM, not being physically active, and it is possible that the results would have differed in a different setting and with a different population. The extent to which the categories of this study can be generalised to other populations must be judged by the reader.

\section{IMPLICATIONS}

Exercise has been shown to improve pain and physical function in FM, and there is a strong recommendation for exercise as first choice treatment in FM. The present results highlight the complexity of both personal and environmental factors promoting the ability to be physically active when living with chronic pain. This underlines the importance of practitioners using a person-centred approach, in which rehabilitation programmes are designed in partnership with the person and based on their preferences. The initiation and maintenance of physical activity habits would be facilitated by continuous access to suitable exercise facilities as well as support from knowledgeable healthcare providers.

\section{CONCLUSION}

In this study, several personal and environmental factors were shown to promote the ability to be physically active when living with pain and other symptoms of FM. The participants explained that although they had a desire to be physically active, they needed support and guidance from a professional with adequate knowledge to help them find the proper level of exercise. They also 
expressed a need for the professional to understand their preferences, and to use these preferences as a basis for creating the proper conditions, helping them learn to manage pain and supporting them in getting the exercise done.

Acknowledgements The authors would like to thank Birgitta Andersson, medical secretary at Närhälsan Herrljunga Primary Healthcare centre for transcribing the interviews and the persons with FM who participated in this study for giving their time and sharing their experiences.

Contributors $\mathrm{AL}$ and $\mathrm{KM}$ conceived the research idea and study design. AL recruited the participants and conducted the initial derivation of meaning units. AL, $\mathrm{CF}$ and KM performed the analysis. AL produced an initial draft of the manuscript. AL, CF and KM commented on and edited the manuscript and approved the final version of the manuscript.

Funding This work was supported by the University of Gothenburg Centre for Person-Centred Care (www.gpcc.gu.se), The Healthcare Board, Region Västra Götaland (Hälso- och sjukvårdsstyrelsen), the Local Research and Development Council, Södra Älvsborg and Wilhelm and Martina Lundgrens Vetenskapsfond.

Competing interests None declared.

Patient consent for publication Not required.

Ethics approval The study was approved by the Regional Ethical Review Board in Gothenburg (ref. 060-16). Oral and written information was given to all participants and written consent was obtained from all participants.

Provenance and peer review Not commissioned; externally peer reviewed.

Data availability statement No data are available.

Open access This is an open access article distributed in accordance with the Creative Commons Attribution Non Commercial (CC BY-NC 4.0) license, which permits others to distribute, remix, adapt, build upon this work non-commercially, and license their derivative works on different terms, provided the original work is properly cited, appropriate credit is given, any changes made indicated, and the use is non-commercial. See: http://creativecommons.org/licenses/by-nc/4.0/.

\section{ORCID iD}

Anette Larsson http://orcid.org/0000-0002-0405-3877

\section{REFERENCES}

1 Queiroz LP. Worldwide epidemiology of fibromyalgia. Curr Pain Headache Rep 2013;17:356.

2 Wolfe F, Ross K, Anderson J, et al. The prevalence and characteristics of fibromyalgia in the general population. Arthritis Rheum 1995;38:19-28.

3 Mannerkorpi K, Burckhardt CS, Bjelle A. Physical performance characteristics of women with fibromyalgia. Arthritis Care Res 1994;7:123-9.

4 Henriksen M, Lund $\mathrm{H}$, Christensen $\mathrm{R}$, et al. Relationships between the fibromyalgia impact questionnaire, tender point count, and muscle strength in female patients with fibromyalgia: a cohort study. Arthritis Rheum 2009;61:732-9.

5 Góes SM, Leite N, Shay BL, et al. Functional capacity, muscle strength and falls in women with fibromyalgia. Clin Biomech 2012;27:578-83.

6 Henriksson C, Gundmark I, Bengtsson A, et al. Living with fibromyalgia. consequences for everyday life. Clin J Pain 1992;8:138-44

7 Wolfe F, Smythe HA, Yunus MB, et al. The American College of rheumatology 1990 criteria for the classification of fibromyalgia. Report of the multicenter criteria Committee. Arthritis Rheum 1990;33:160-72.

8 Caspersen CJ, Powell KE, Christenson GM. Physical activity, exercise, and physical fitness: definitions and distinctions for healthrelated research. Public Health Rep 1985;100:126-31.

9 World Health Organization. Global recommendations on physical activity for health. Geneva: World Health Organisation, 2010.

10 Kruk J. Health and economic costs of physical inactivity. Asian Pac J Cancer Prev 2014;15:7499-503.

11 McLoughlin MJ, Colbert LH, Stegner AJ, et al. Are women with fibromyalgia less physically active than healthy women? Med Sci Sports Exerc 2011;43:905-12.
12 Macfarlane GJ, Kronisch C, Dean LE, et al. EULAR revised recommendations for the management of fibromyalgia. Ann Rheum Dis 2016.

13 Mannerkorpi K, Iversen MD. Physical exercise in fibromyalgia and related syndromes. Best Pract Res Clin Rheumatol 2003;17:629-47.

14 Segura-Jiménez V, Borges-Cosic M, Soriano-Maldonado A, et al. Association of sedentary time and physical activity with pain, fatigue, and impact of fibromyalgia: the al-Ándalus study. Scand J Med Sci Sports 2017;27:83-92.

15 Mannerkorpi K, Nordeman L, Ericsson A, et al. Pool exercise for patients with fibromyalgia or chronic widespread pain: a randomized controlled trial and subgroup analyses. J Rehabil Med 2009;41:751-60.

16 Mannerkorpi K, Nyberg B, Ahlmén M, et al. Pool exercise combined with an education program for patients with fibromyalgia syndrome. A prospective, randomized study. J Rheumatol 2000;27:2473-81.

17 Mannerkorpi K, Nordeman L, Cider A, et al. Does moderate-to-high intensity Nordic walking improve functional capacity and pain in fibromyalgia? A prospective randomized controlled trial. Arthritis Res Ther 2010;12:R189.

18 Larsson A, Palstam A, Löfgren M, et al. Resistance exercise improves muscle strength, health status and pain intensity in fibromyalgia--a randomized controlled trial. Arthritis Res Ther 2015;17:161.

19 Busch AJ, Webber SC, Brachaniec M, et al. Exercise therapy for fibromyalgia. Curr Pain Headache Rep 2011;15:358-67.

20 Mannerkorpi K, Ahlmén M, Ekdahl C. Six- and 24-month follow-up of pool exercise therapy and education for patients with fibromyalgia. Scand J Rheumatol 2002;31:306-10.

21 Mannerkorpi K, Nordeman L, et al. Does moderate-to-high aerobic exercise result in better improvement of body impairments and pain than low-intensive exercise in FM? A prospective randomised controlled trial Arthritis Research \& Therapy. Arthritis Res Ther. 2010;12:R189.

22 Verhagen E, Engbers L. The physical therapist's role in physical activity promotion. Br J Sports Med 2009;43:99-101.

23 DiCicco-Bloom B, Crabtree BF. The qualitative research interview. Med Educ 2006;40:314-21.

24 Krippendorff K. Content analysis: an introduction to its methodology. Thousand oaks,CA: Sage, 2004.

25 Hedin PJ, Hamne M, Burckhardt CS, et al. The fibromyalgia impact questionnaire, a Swedish translation of a new tool for evaluation of the fibromyalgia patient. Scand J Rheumatol 1995;24:69-75.

26 Bennett RM, Bushmakin AG, Cappelleri JC, et al. Minimal clinically important difference in the fibromyalgia impact questionnaire. $J$ Rheumatol 2009;36:1304-11.

27 Mannerkorpi K, Hernelid C. Leisure time physical activity instrument and physical activity at home and work instrument. development, face validity, construct validity and test-retest reliability for subjects with fibromyalgia. Disabil Rehabil 2005;27:695-701.

28 Graneheim UH, Lundman B. Qualitative content analysis in nursing research: concepts, procedures and measures to achieve trustworthiness. Nurse Educ Today 2004;24:105-12.

29 Graneheim UH, Lindgren B-M, Lundman B. Methodological challenges in qualitative content analysis: a discussion paper. Nurse Educ Today 2017;56:29-34.

30 Staud R, Robinson ME, Price DD. Isometric exercise has opposite effects on central pain mechanisms in fibromyalgia patients compared to normal controls. Pain 2005;118:176-84.

31 Damsgård E, Dewar A, Røe C, et al. Staying active despite pain: pain beliefs and experiences with activity-related pain in patients with chronic musculoskeletal pain. Scand J Caring Sci 2011;25:108-16.

32 Larsson MEH, Nordholm LA, Öhrn I. Patients' views on responsibility for the management of musculoskeletal disorders--a qualitative study. BMC Musculoskelet Disord 2009;10:103.

33 Loeppenthin K, Esbensen B, Ostergaard M, et al. Physical activity maintenance in patients with rheumatoid arthritis: a qualitative study. Clin Rehabil 2014;28:289-99.

34 Feldthusen C, Mannerkorpi K. Factors of importance for reducing fatigue in persons with rheumatoid arthritis: a qualitative interview study. BMJ Open 2019;9:e028719.

35 Bandura A. Self-efficacy: the exercise of control. New York: Freeman, 1997.

36 Oliver K, Cronan T. Predictors of exercise behaviors among fibromyalgia patients. Prev Med 2002;35:383-9.

37 Joelsson M, Bernhardsson S, Larsson MEH. Patients with chronic pain may need extra support when prescribed physical activity in primary care: a qualitative study. Scand J Prim Health Care 2017;35:64-74.

38 Ekman I, Swedberg K, Taft C, et al. Person-centered care--ready for prime time. Eur J Cardiovasc Nurs 2011;10:248-51. 
39 Swärdh E, Biguet G, Opava CH. Views on exercise maintenance: variations among patients with rheumatoid arthritis. Phys Ther 2008;88:1049-60.

40 Karlsson L, Gerdle B, Takala E-P, et al. Experiences and attitudes about physical activity and exercise in patients with chronic pain: a qualitative interview study. J Pain Res 2018;11:133-44.

41 Löfgren M, Ekholm J, Öhman A. 'A constant struggle': successful strategies of women in work despite fibromyalgia. Disabil Rehabil 2006;28:447-55
42 McCracken LM. Learning to live with the pain: acceptance of pain predicts adjustment in persons with chronic pain. Pain 1998;74:21-7.

43 Lachapelle DL, Lavoie S, Boudreau A. The meaning and process of pain acceptance. perceptions of women living with arthritis and fibromyalgia. Pain Res Manag 2008;13:201-10.

44 Mannerkorpi K, Kroksmark T, Ekdahl C. How patients with fibromyalgia experience their symptoms in everyday life. Physiother Res Int 1999;4:110-22. 